\title{
ANÁLISE DE CRESCIMENTO DE AÇAIZEIROS EM ÁREAS DE VÁRZEA DO ESTUÁRIO AMAZÔNICO'1
}

\author{
OSCAR LAMEIRA NOGUEIRA² e HERÁCLITO EUGÊNIO OLIVEIRA DA CONCEIÇÃO
}

\begin{abstract}
RESUMO - Com o objetivo de analisar o crescimento de açaizeiros (Euterpe oleracea Mart.) em áreas de várzea submetidas à exploração de palmito, visando ao manejo racional da espécie, foi realizado estudo no município de Igarapé-Miri, Pará. Foram amostrados todos os estipes e rebrotes de três plantas de cada idade após o corte (12, 24, 36 e 48 meses após a extração do palmito), e avaliada a matéria seca dos seguintes componentes: folíolos, ráquis + pecíolos, bainhas + palmitos, e estipes. As plantas selecionadas são representativas da população quanto à altura média dos estipes, número de perfilhos e número de folhas. A produção de matéria seca total foi de 2,68, 5,25, 9,23 e 42,91 kg por planta no $12^{\circ}, 24^{\circ}, 36^{\circ}$ e $48^{\circ}$ mês após a extração do palmito, respectivamente. Nos açaizais recém-explorados, os folíolos representaram cerca de $40 \%$ do peso total da parte aérea da planta, e os estipes, $10 \%$. Após 48 meses, em açaizais recompostos, os estipes foram responsáveis por $73 \%$ do peso total da parte aérea da planta, e os folíolos, somente por 10\%. Doze meses após o corte do palmito, os açaizeiros apresentavam altura média de $1 \mathrm{~m}$, e atingiram mais de $3 \mathrm{~m}$ após 48 meses.
\end{abstract}

Termos para indexação: conteúdo de matéria seca, área foliar, várzea, propagação vegetativa, taxa de crescimento, fenologia.

\section{GROWTH ANALYSIS OF AÇAÍ PALM TREES (EUTERPE OLERACEA MART.) IN FLOODPLAIN OF AMAZON ESTUARY}

\begin{abstract}
With the objective of analyzing the palm heart tree growth, in lowland areas submitted to the palm heart exploration, aiming to subsidize the rational handling of the species, a study was accomplished in the county of Igarapé-Miri, PA, Brazil. All of the stems and new budding of three plants of different ages $(12,24,36$ and 48 months after heart extraction) were sampled, and the following components were collected for dry matter evaluation: leaflets, rachis + petioles, sheath + palm hearts and trunks. Representative clumps of the population were selected based on the medium height of the trunks, and number of shoots and leaves. The total dry matter production was $2.68,5.25,9.23$ and $42.91 \mathrm{~kg}$ per plant at 12,24, 36 and 48 months after the palm heart extraction, respectively. In the recently explored palm heart areas the leaflets represented about $40 \%$ of the total weight of the aerial part of the plant and the trunks $10 \%$. After 48 months, in recomposed areas, the trunks were responsible for $73 \%$ of the total weight of the plant, while the leaflets only for $10 \%$. Twelve months after the cutting of palm heart, the plants presented medium height of $1 \mathrm{~m}$, and reached more than $3 \mathrm{~m}$ after 48 months.
\end{abstract}

Index terms: dry matter content, leaf area, lowland, vegetative propagation, growth rate, phenology.

\section{INTRODUÇÃO}

As palmeiras constituem-se numa das plantas mais utilizadas nas regiões tropicais, e algumas espécies

\footnotetext{
${ }^{1}$ Aceito para publicação em 17 de janeiro de 2000.

${ }^{2}$ Eng. Agrôn., D.Sc., Embrapa-Centro de Pesquisa Agroflorestal da Amazônia Oriental (CPATU), Caixa Postal 48, CEP 66017-970 Belém, PA. E-mail: oscar@cpatu.embrapa.br

${ }^{3}$ Eng. Agrôn., M.Sc., Embrapa-CPATU.

E-mail: heraclit@cpatu.embrapa.br
}

evidenciam-se pela importância socioeconômica que representam, podendo-se destacar o coqueiro e o dendezeiro, os quais são responsáveis pelo suprimento de grande quantidade de matéria-prima industrial. Nos locais onde as palmeiras ocorrem de forma espontânea, com abundância em quantidade e número de espécies, chegam a dominar a paisagem das florestas nativas amazônicas (Moore, 1973). Pela importância que representam para a subsistência das populações locais, são exploradas com tal intensida- 
de em algumas áreas, que chegam a ocasionar dificuldades para a sua regeneração.

A instalação das indústrias processadoras de palmito no estuário amazônico, a partir dos anos 60, deu início ao processo de extração de palmito nos açaizais nativos de várzea, atingindo, atualmente, elevada intensidade de exploração, em razão da grande quantidade de matéria-prima demandada pelas fábricas de toda a região.

A forma com que a espécie vem sendo explorada tem ocasionado, em algumas áreas, a sua degradação e, conseqüentemente, a redução da oferta de frutos, os quais são componentes importantes para a alimentação das populações locais.

Nas áreas mais distantes dos grandes centros urbanos, os açaizais nativos são explorados com maior ênfase para a produção de palmito, cuja pressão de corte pode ser intensa, chegando a prejudicar a regeneração das plantas. Estudos realizados por Pollak et al. (1995) constataram que os extratores de palmito adotam o intervalo de um a dois anos de um corte para outro na mesma área, embora tenham encontrado casos com intervalo de apenas seis meses. Para Costa et al. (1973), o ciclo de corte do palmito em açaizais nativos de várzea deve ser de três anos, enquanto para Calzavara (1976) deve ser de pelo menos quatro anos, quando se pratica o corte raso.

Os estudos sobre análise de crescimento de espécies vegetais possibilitam acompanhar o desenvolvimento das plantas como um todo e a contribuição dos diferentes órgãos no crescimento total, permitindo conhecer o seu funcionamento e suas estruturas (Benincasa, 1988; Liedgens, 1993). A análise de crescimento é, também, um instrumento que tem sido usado com o objetivo primordial de gerar descrição clara do padrão de crescimento da planta ou de partes dela, permitindo comparações entre situações distintas, podendo ser aplicada às mais diversas modalidades de estudos (Hunt, 1978; Beadle, 1993; Liedgens, 1993).

O presente trabalho teve como objetivo analisar o crescimento de açaizeiros em áreas de várzea submetidas à exploração de palmito, com vistas a compreender o processo de regeneração e subsidiar o manejo racional da espécie.

\section{MATERIAL E MÉTODOS}

O estudo foi realizado no município de Igarapé-Miri, microrregião homogênea de Cametá, Estado do Pará. Ali foram amostrados todos os estipes e rebrotes de três plantas de cada açaizal com diferentes idades de regeneração após a extração do palmito (12, 24, 36 e 48 meses), e coletados, separadamente, os seguintes componentes: folíolos, ráquis + pecíolos, bainhas+palmitos e estipes. Cada planta foi amostrada de uma parcela de $200 \mathrm{~m}^{2}$ contendo cada cerca de 30 plantas.

As plantas foram cortadas à altura do colo, e seus componentes, separados em folíolos, ráquis + pecíolos, bainhas + palmitos e estipe exposto. Cada componente foi imediatamente pesado, para determinação do peso da matéria fresca, de onde foram retiradas amostras de, aproximadamente, $100 \mathrm{~g}$, acondicionadas em sacos de papel e colocadas para secar em estufa com circulação forçada de ar na temperatura de $65^{\circ} \mathrm{C} \mathrm{a} 70^{\circ} \mathrm{C}$, até atingirem peso constante, e posterior determinação da matéria seca.

A área foliar foi determinada por meio do produto do comprimento e da largura dos folíolos, multiplicado pelo fator 0,6854. Este foi obtido dividindo-se a área foliar real do folíolo pela área do retângulo formado pelo comprimento e largura dos folíolos, em amostras de folíolos de folhas de açaizeiros com diferentes idades.

As fórmulas utilizadas para obter as diversas taxas de crescimento da planta, com base na produção de matéria seca e na área foliar, possibilitando analisar o crescimento de açaizeiros remanescentes em áreas de extração de palmito, foram as seguintes:

$\mathrm{TCA}=\left(\mathrm{P}_{2}-\mathrm{P}_{1}\right) /\left(\mathrm{t}_{2}-\mathrm{t}_{1}\right)$;

$\mathrm{TCR}=\left(\mathrm{L}_{\mathrm{n}} \mathrm{P}_{2}-\mathrm{L}_{\mathrm{n}} \mathrm{P}_{1}\right) /\left(\mathrm{t}_{2}-\mathrm{t}_{1}\right)$;

$\mathrm{TCR}_{\mathrm{AF}}=\left(\mathrm{L}_{\mathrm{n}} \mathrm{AF}_{2}-\mathrm{L}_{\mathrm{n}} \mathrm{AF} \mathrm{F}_{1}\right) /\left(\mathrm{t}_{2}-\mathrm{t}_{1}\right)$;

$\mathrm{TAL}=\left[\left(\mathrm{P}_{2}-\mathrm{P}_{1}\right) /\left(\mathrm{AF}_{2}-\mathrm{AF}_{1}\right)\right] *\left[\left(\mathrm{~L}_{\mathrm{n}} \mathrm{AF}_{2}-\mathrm{L}_{\mathrm{n}} \mathrm{AF}_{1}\right) /\left(\mathrm{t}_{2}-\mathrm{t}_{1}\right)\right]$; $\mathrm{RAF}=\left(\mathrm{AF}_{1}+\mathrm{AF}_{2}\right) /\left(\mathrm{P}_{1}+\mathrm{P}_{2}\right)$,

onde TCA é a taxa de crescimento absoluto; TCR é a taxa de crescimento relativo; $\mathrm{TCR}_{\mathrm{AF}}$ é a taxa de crescimento relativo da área foliar; TAL é a taxa de assimilação líquida; RAF é a razão de área foliar; $P$ é o peso total da matéria seca da planta; $\mathrm{AF}$ é a área foliar total da planta; te o tempo de regeneração, e 1 e 2 referem-se a duas amostragens sucessivas (Radford, 1967; Causton \& Venus, 1981; Beadle, 1982; Benincasa, 1988).

As áreas de açaizais estudadas caracterizam-se pela elevada concentração de plantas, tendo em vista a forma com que são manejadas pelas populações ribeirinhas, as quais praticam desbaste seletivo das espécies sem interesse comercial e enriquecimento com açaizeiros. O clima da região, segundo a classificação de Köppen, é do tipo Ami - tropical chuvoso com pequeno período seco, preci- 
pitação pluvial média anual variando de 2.500 a $3.000 \mathrm{~mm}$ e ocorrendo com maior intensidade durante os meses de dezembro a junho. A temperatura média anual é de $26^{\circ} \mathrm{C}$, e a umidade relativa do ar nunca é inferior a $80 \%$ (Bastos et al., 1986).

O solo predominante nas áreas de várzea do estuário amazônico é do tipo Glei Pouco Húmico, resultante do acúmulo de sedimentos deixados pelas águas das marés, mal drenados, elevado teor de argila, baixa saturação de bases e pH ligeiramente ácido (Falesi, 1986). Os resultados das análises estão apresentados na Tabela 1.

A análise de variância foi realizada utilizando-se o método dos quadrados mínimos, e para a comparação de médias foi aplicado o teste de Tukey, a 5\% de probabilidade. O modelo escolhido para os ajustes de curvas foi a equação polinomial linear ou quadrática, em função do coeficiente de determinação $\left(\mathrm{r}^{2}\right)$.

\section{RESULTADOS E DISCUSSÃO}

Para a condução dos trabalhos que possibilitaram a análise de crescimento dos açaizeiros, foram selecionadas, de cada uma das áreas em estudo, localizadas às margens do rio Meruú-Açu, três plantas completas, representativas da população quanto à altura média dos estipes, número de perfilhos e número de folhas, amostradas na mesma época (Tabela 2).

A produção total de biomassa fresca da parte aérea das plantas, observada em açaizais nativos de várzea com diferentes idades de regeneração, foi de $10,6 \mathrm{~kg} /$ planta, $27,6 \mathrm{~kg} /$ planta, $34,7 \mathrm{~kg} /$ planta e

TABELA 1. Características químicas de amostras de solos, coletadas a duas profundidades, em açaizais nativos de várzea, após o corte do palmito. Igarapé-Miri, Pará, 1997.

\begin{tabular}{lcc}
\hline Característica & \multicolumn{2}{c}{ Profundidade } \\
\cline { 2 - 3 } & $(0-12 \mathrm{~cm})$ & $(13-30 \mathrm{~cm})$ \\
\hline Matéria orgânica $\left(\mathrm{g} \mathrm{kg}^{-1}\right)$ & 74,5 & 24,8 \\
$\mathrm{P}\left(\mathrm{mg} \mathrm{dm}^{-3}\right)$ & 9,5 & 1,7 \\
$\mathrm{~K}^{+}\left(\mathrm{mmol}_{\mathrm{c}} \mathrm{dm}^{-3}\right)$ & 1,4 & 0,8 \\
$\mathrm{pH} \mathrm{em} \mathrm{H} \mathrm{O}$ & 5,4 & 5,7 \\
$\mathrm{Ca}^{2+}\left(\mathrm{mmol}_{\mathrm{c}} \mathrm{dm}^{-3}\right)$ & 75 & 49 \\
$\mathrm{Mg}^{2+}\left(\mathrm{mmol}_{\mathrm{c}} \mathrm{dm}^{-3}\right)$ & 35 & 37 \\
$\mathrm{Al}^{3+}\left(\mathrm{mmol}_{\mathrm{c}} \mathrm{dm}^{-3}\right)$ & 10 & 14 \\
\hline
\end{tabular}

$112,8 \mathrm{~kg} /$ planta com 12, 24, 36 e 48 meses após a extração do palmito, respectivamente. A porcentagem de matéria seca total da planta é de, aproximadamente, $25 \%$, até a idade de 36 meses após o corte do palmito, alcançando $38 \%$ quando a planta atinge plenamente a fase adulta, cuja maior parte é constituída de estipes lenhosos. Os dados referentes à produção de matéria seca nos diferentes componentes da parte aérea das plantas (folíolos, ráquis + pecíolo, bainhas + palmitos, estipes e total), de acordo com a idade de regeneração após o corte do palmito, encontram-se na Tabela 3.

A comparação entre as médias, pelo teste de Tukey, evidencia que houve diferenças significativas entre as idades de regeneração, notadamente entre os períodos extremos, com exceção do estipe, que foi diferente apenas aos 48 meses após o corte do palmito. A produção de matéria seca, em todos os componentes da planta de açaizeiro, foi sempre ascendente com o decorrer do tempo, atingindo o total de 42,91 kg/planta, correspondente a 68,65 t/ha, aos 48 meses após a extração do palmito (Tabela 3 ). Nas áreas recém-cortadas, os folíolos e os estipes respondem por $38,4 \%$ e $11,6 \%$, respectivamente, do total de matéria seca da parte aérea do açaizeiro, ao passo que aos 48 meses após o corte do palmito, os estipes representam 73,3\%, e os folíolos, somente $10,5 \%$ (Fig. 1).

Os componentes ráquis + pecíolos e bainhas + palmitos, embora apresentem incremento na produção de matéria seca ao longo do período, mostramse decrescentes em termos de porcentagem em relação ao peso total de matéria seca da planta (Fig. 1).

As equações de regressão com os respectivos coeficientes de determinação $\left(\mathrm{r}^{2}\right)$ para a produção de matéria seca total e nos diversos componentes de plantas de açaizeiros, com várias idades de regeneração após o corte do palmito, são observadas na Fig. 2. As curvas obtidas evidenciam que o peso da matéria seca dos estipes é o principal fator que determina o peso da matéria seca total da planta durante os diferentes períodos de regeneração dos açaizeiros.

Aos 48 meses de regeneração os açaizais encontram-se plenamente reabilitados, com a produção de matéria seca obedecendo à seguinte ordem decrescente: estipes > folíolos > bainhas + palmitos > 
TABELA 2. Características das plantas utilizadas para a realização dos estudos sobre análise de crescimento em açaizais nativos de várzea com diferentes idades de regeneração, após o corte do palmito. IgarapéMiri, Pará, 1997.

\begin{tabular}{lcccc}
\hline Característica & 12 meses & 24 meses & 36 meses & 48 meses \\
\hline Altura do estipe $(\mathrm{cm})$ & 102,6 & 123,5 & 194,6 & 315,6 \\
Diâmetro do estipe $(\mathrm{cm})$ & - & 7,08 & 8,58 & 11,05 \\
Número de estipes/planta & 1,74 & 3,21 & 2,93 & 3,77 \\
Número de folhas/estipe & 7,97 & 8,02 & 8,51 & 7,63 \\
Número de plantas/parcela & 26 & 27 & 34 & 32 \\
\hline
\end{tabular}

TABELA 3. Produção de matéria seca nos diferentes componentes da planta, em quilograma/planta, em açaizais nativos com diferentes idades de regeneração após o corte do palmito. Igarapé-Miri, Pará, 19971.

\begin{tabular}{cccccr}
\hline $\begin{array}{c}\text { Idade } \\
\text { (meses) }\end{array}$ & Folíolos & Ráquis + pecíolos & Bainhas + palmitos & Estipes & Total \\
\hline 12 & $1,03 \mathrm{a}$ & $0,42 \mathrm{a}$ & $0,92 \mathrm{a}$ & $0,31 \mathrm{a}$ & $2,68 \mathrm{a}$ \\
24 & $1,89 \mathrm{a}$ & $0,90 \mathrm{a}$ & $1,34 \mathrm{ab}$ & $1,12 \mathrm{a}$ & $5,25 \mathrm{a}$ \\
36 & $2,18 \mathrm{ab}$ & $1,70 \mathrm{ab}$ & $3,75 \mathrm{bc}$ & $1,60 \mathrm{a}$ & $9,23 \mathrm{a}$ \\
48 & $4,49 \mathrm{~b}$ & $2,54 \mathrm{~b}$ & $4,39 \mathrm{c}$ & $31,49 \mathrm{~b}$ & $42,91 \mathrm{~b}$ \\
\hline
\end{tabular}

${ }^{1}$ Médias seguidas de letras iguais, na mesma coluna, não diferem significativamente entre si, a 5\% de probabilidade, pelo teste Tukey.

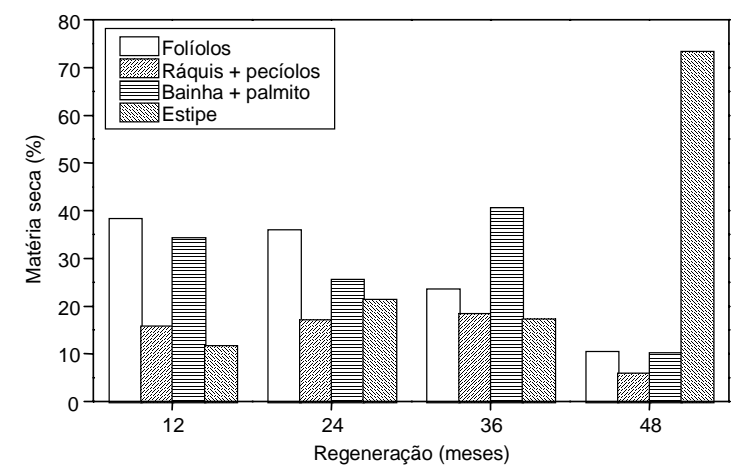

FIG. 1. Produção de matéria seca, em porcentagem, nos diferentes componentes de açaizeiros de várzea submetidos ao extrativismo do palmito. Igarapé-Miri, Pará, 1997.

ráquis + pecíolos (Fig. 2). Houve um efeito quadrático da idade de regeneração após o corte do palmito sobre a produção de matéria seca total e dos diversos componentes da planta.

Analisando-se os resultados de produção de matéria seca nos diversos componentes das plantas de açaizeiros, constatou-se que esta variável é determinada principalmente pelos estipes. Essa situação torna-se mais evidente à medida que as plantas desen-

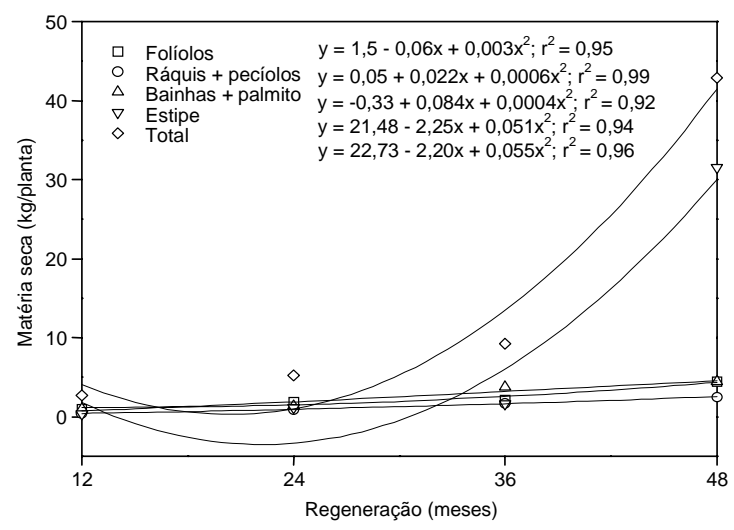

FIG. 2. Produção de matéria seca em açaizais nativos de várzea submetidos ao extrativismo do palmito. Igarapé-Miri, Pará, 1997.

volvem-se e passam a contar com maior número de estipes. Estudos realizados por Viégas (1993) permitiram inferir que em dendezeiros a produção de matéria seca da parte aérea de uma planta é de seis a oito vezes maior que em açaizeiros, porém, por hectare, as quantidades equivalem-se em virtude do menor número de plantas verificado nos dendezais, quando comparadas às áreas de açaizais nativos. Considerando os diferentes componentes das plan- 
tas, Viégas (1993) constatou que, a partir do sexto ano de idade, a produção de matéria seca dos estipes dos dendezeiros representa cerca de $40 \%$ do total da planta, enquanto os folíolos correspondem a $13 \%$, aproximadamente. Em açaizeiros adultos, os dois componentes representam $83,8 \%$ da matéria seca total da parte aérea da planta.

Pela Tabela 4 observa-se que o comprimento médio das folhas não apresentou diferenças significativas até a idade de 36 meses após o corte do palmito, mas ao atingir o comprimento de $278,8 \mathrm{~cm}$, aos 48 meses, mostrou-se diferente de quando estava com 24 meses. O número de folíolos por folha, por sua vez, não diferiu significativamente $(\mathrm{P}>0,05)$ entre as idades de regeneração estudadas. A área foliar estimada das plantas somente mostrou diferenças significativas entre a menor e a maior idade de regeneração, atingindo $30,52 \mathrm{~m}^{2} /$ planta aos 48 meses, em comparação com os $6,71 \mathrm{~m}^{2} /$ planta quando ainda encontravam-se com 12 meses após a extração do palmito. A área foliar por hectare, considerando a idade de regeneração dos açaizeiros, variou de $8.921,9$ a 48.841,1 m². A equação de regressão referente à área foliar, em razão das diferentes idades de regeneração, está contida na Fig. 3. Observa-se que houve um comportamento linear do tempo de regeneração dos açaizeiros sobre a área foliar, demonstrando que a área foliar máxima da planta ainda não foi alcançada até os 48 meses de idade após o corte.

As taxas de crescimento de açaizeiros calculadas com os dados primários de peso da matéria seca da parte aérea e da estimativa da área foliar, obtidas ao longo do ciclo de regeneração das plantas, estão apre-

TABELA 4. Comprimento da ráquis (cm), número de folíolos por folha e área foliar ( $\left.\mathrm{m}^{2} / \mathrm{planta}\right)$ de açaizais nativos com diferentes idades de regeneração após o corte do palmito. Igarapé-Miri, Pará, 1997¹.

\begin{tabular}{cccc}
\hline $\begin{array}{l}\text { Idade } \\
\text { (meses) }\end{array}$ & $\begin{array}{c}\text { Comprimento } \\
\text { da ráquis }\end{array}$ & $\begin{array}{c}\text { Número de } \\
\text { folíolos/folha }\end{array}$ & Área foliar \\
\hline 12 & $197,3 \mathrm{ab}$ & $76,0 \mathrm{a}$ & $6,71 \mathrm{a}$ \\
24 & $190,3 \mathrm{a}$ & $81,9 \mathrm{a}$ & $16,76 \mathrm{ab}$ \\
36 & $264,6 \mathrm{ab}$ & $59,0 \mathrm{a}$ & $20,14 \mathrm{ab}$ \\
48 & $278,8 \mathrm{~b}$ & $85,2 \mathrm{a}$ & $30,52 \mathrm{~b}$ \\
\hline
\end{tabular}

${ }^{1}$ Médias seguidas de letras iguais, na mesma coluna, não diferem significativamente entre si, a 5\% de probabilidade, pelo teste Tukey. sentadas na Tabela 5. A taxa de crescimento absoluto (TCA), que é a variação ou o incremento entre duas amostragens ao longo do ciclo da planta, apresentou resultados que evidenciam a grande velocidade de crescimento dos açaizeiros a partir de 36 meses após o corte do palmito, com uma taxa duas vezes e meia maior que a média observada em todo o período, que foi de 13,41 kg/ano. A taxa de crescimento relativo (TCR), que depende, fundamentalmente, da área foliar útil para a fotossíntese e da taxa de fotossíntese líquida, também apresentou variação ao longo do ciclo de observações, comportando-se de forma semelhante à taxa de crescimento absoluto (TCA).

A taxa de crescimento relativo da área foliar $\left(\mathrm{TCR}_{\mathrm{AF}}\right)$ e a razão de área foliar (RAF), parâmetros determinados em maior grau pela superfície foliar, expõem valores decrescentes com o aumento do tempo de regeneração dos açaizeiros. A taxa de assimilação líquida (TAL) que expressa a fotossíntese, em termos de matéria seca produzida por área foliar por unidade de tempo, por sua vez, apresentou resultados crescentes ao longo do tempo.

Os valores médios obtidos quanto à taxa de crescimento relativo (TCR), taxa de assimilação líquida (TAL) e razão de área foliar (RAF) dos açaizeiros, ao longo do período de 48 meses de regeneração, são inferiores aos observados por Clement (1995) ao analisar o crescimento em várias progênies de pupunheiras cultivadas em duas localidades do Havaí

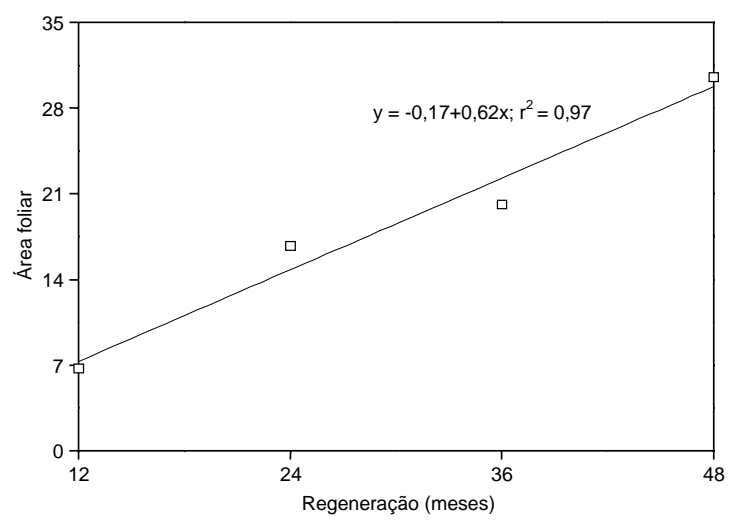

FIG. 3. Área foliar ( $\mathrm{m}^{2} /$ planta) em açaizeiros nativos de várzea submetidos ao extrativismo do palmito. Igarapé-Miri, Pará, 1997. 
TABELA 5. Taxa de crescimento absoluto (TCA), taxa de crescimento relativo (TCR), taxa de crescimento relativo da área foliar (TCR $\mathrm{AF}_{\mathrm{AF}}$ ), taxa de assimilação líquida (TAL) e razão de área foliar (RAF) em açaizais nativos de várzea com diferentes idades de regeneração após o corte do palmito. IgarapéMiri, Pará, 1997.

\begin{tabular}{cccccc}
\hline Regeneração & TCA & TCR & TCR $_{\mathrm{AF}}$ & TAL & RAF \\
\hline (meses $)$ & $(\mathrm{kg} / \mathrm{ano})$ & $(\mathrm{kg} / \mathrm{kg} / \mathrm{ano})$ & $\left(\mathrm{m}^{2} / \mathrm{m}^{2} / \mathrm{ano}\right)$ & $\left(\mathrm{kg} / \mathrm{m}^{2} / \mathrm{ano}\right)$ & $\left(\mathrm{m}^{2} / \mathrm{kg}\right)$ \\
$12-24$ & 2,57 & 0,66 & 0,91 & 0,23 & 2,96 \\
$24-36$ & 3,98 & 0,57 & 0,18 & 0,22 & 2,55 \\
$36-48$ & 33,68 & 1,54 & 0,41 & 1,34 & 0,97 \\
\hline Média & 13,41 & 0,92 & 0,50 & 0,59 & 2,16 \\
\hline
\end{tabular}

para produção de palmito. Por outro lado, a área foliar e a taxa de crescimento absoluto (TCA) encontradas nos açaizeiros correspondem ao dobro do valor observado nas referidas pupunheiras.

\section{CONCLUSÕES}

1. Os açaizais nativos de várzea, quatro anos após a extração do palmito, podem ser novamente explorados para a produção de frutos ou palmito.

2. A produção de matéria seca total mostra-se lenta até o 36o mês após o corte do palmito, e apresenta um aumento considerável a partir desta idade; a porção lenhosa dos estipes, a partir desta mesma idade, é a que mais contribui para a produção de matéria seca total entre todas as partes estudadas da planta.

3. As taxas de crescimento absoluto, de crescimento relativo e de assimilação líquida apresentam incrementos mais expressivos a partir do $36^{\circ}$ mês após a extração do palmito.

\section{AGRADECIMENTOS}

Aos engenheiros agrônomos Edgar Iunes Pinheiro e Enilson Solano, e ao engenheiro florestal Manoel Lázaro Trindade de Jesus, pela valiosa colaboração na coleta de dados no campo e na preparação do material para análise.

\section{REFERÊNCIAS}

BASTOS, T.X.; ROCHA, E.J.P. de; ROLIM, P.A.M.; DINIZ, T.D. de A.S.; SANTOS, E.C.R. dos; NOBRE, R.A.A.; CUTRIM, E.M.C.; RIZIO, L.D. de M. O estado atual dos conhecimentos de clima da Amazônia brasileira com finalidade agrícola. In: SIMPÓSIO DO TRÓPICO ÚMIDO, 1., 1984, Belém. Anais. Belém : Embrapa-CPATU, 1986. p.19-36. (Embrapa-CPATU. Documentos, 36).

BEADLE, C.L. Growth analysis. In: HALL, D.O.; SCURLOCK, J.M.O.; BOLHÀR-NORDENKAMPF, H.R.; LEEGOOD, R.C.; LONG, S.P. (Ed.). Photosynthesis and production in a changing environment: a field and laboratory manual. London : Chapmam \& Hall, 1993. p.36-46.

BEADLE, C.L. Plant-growth analysis. In: COOMBS, J.; HALL, D.O. (Ed.). Techniques in bioproductivity and photosynthesis. Oxford : Pergamon, 1982. p.20-25.

BENINCASA, M.M.P. Análise de crescimento de plantas. Jaboticabal : FUNEP, 1988. 43p.

CALZAVARA, B.B.G. As possibilidades do açaizeiro no estuário amazônico. In: SIMPOSIO INTERNACIONAL SOBRE PLANTAS DE INTERÉS ECONÓMICO DE LA FLORA AMAZÓNICA, 1972, Belém. [Trabajos presentados]. Turrialba : IICA, 1976. p.165-207.

CAUSTON, D.R.; VENUS, J.C. The biometry of plant growth. London : E. Arnold, 1981. 307p.

CLEMENT, C.R. Growth and genetic analysis of pejibaye (Bactris gasipaes Kunth, Palmae) in Hawaii. Honolulu : University of Hawaii at Manoa, 1995. 221p.

COSTA, A.C.A.; SOUZA, C.B. de; BASTOS, L.M.P.; FROTA, M.I. da; FERREIRA, R.M.; DIAS, S. da F. Projeto palmito de açaí Ltda. 2.ed. Belém : IDESP, 1973. 283p.

FALESI, I.C. Estado atual de conhecimento de solos da Amazônia brasileira. In: SIMPÓSIO DO TRÓPICO 
ÚMIDO, 1., 1984, Belém. Anais. Belém : EmbrapaCPATU, 1986. p.168-191. (Embrapa-CPATU. Documentos, 36).

HUNT, R. Plant growth analysis. London : E. Arnold, 1978. 67p.

LIEDGENS, M.M. Modelos numéricos para a descrição do crescimento da planta de soja (Glycine max L. Merrill, cultivar IAC-15) em condições sazonais diferenciadas. Campinas : Unicamp, 1993. 101p. Dissertação de Mestrado.

MOORE, J.R. The major groups of palms and their distribution. Gentes Herbarum, Ithaca, v.11, p.701$732,1973$.
POLLAK, H.; MATTOS, M.; UHL, C. A profile of palm heart extraction in the Amazon estuary. Human Ecology, New York, v.23, n.3, p.357-385, 1995.

RADFORD, P.J. Growth analysis formulae: their use and abuse. Crop Science, Madison, v.7, n.3, p.171-175, 1967.

VIÉGAS, I. de J.M. Crescimento do dendezeiro (Elaeis guineensis Jacq), concentração, conteúdo e exportação de nutrientes nas diferentes partes de plantas com 2 a 8 anos de idade, cultivadas em Latossolo Amarelo distrófico, Tailândia, Pará. Piracicaba : ESALQ, 1993. 217p. Tese de Doutorado. 